\title{
Influence of Roller Ball Tool in Single Point Incremental Forming of Polymers
}

\author{
Karthik THANGAVEL, Rajenthirakumar DURAISWAMY, Srinivasan NAGARAJAN, Sridhar RAMASAMY
}

\begin{abstract}
Polymers defend the metals in making complex geometries because of their strength to weight ratio. Utilizing the conventional process has become a challenge in manufacturing customized products. Increase in demand of tailored products in minimum quantities with preferred quality creates the need for developing new techniques. Incremental forming process is an emerging flexible technology that can obtain pre-defined profiles through deformation of metals and polymers in desired thickness at a reasonable cost. In this work, single point incremental forming (SPIF) of different polymer materials is done using roller ball tool and modest fixture system. Materials such as polyvinyl chloride (PVC), polypropylene (PP), polycarbonate (PC), high density poly ethylene (HDPE) are considered for this investigation due to high applications in automobile and biomedical area. The experiments are designed to analyse the influence of variable process parameters such as tool diameter, step size, spindle speed and sheet thickness. The analysis is carried out by characterizing the formability with depth of failure, thickness distribution, surface roughness and microstructure evaluation. Based on the result, the spindle speed and sheet thickness show high response in formability, surface roughness and depth of failure. The tool diameter has a significant effect on the surface roughness. PVC shows the springback resistance and cracks are observed in the circumferential route on the transition area among the bottom and side wall portion.
\end{abstract}

Keywords: failure analysis; formability; microstructure; roller ball tool; thickness distribution

\section{INTRODUCTION}

Since the conventional polymer processing techniques have high processing and tooling cost, the mass production is appropriate rather than small batch production or prototype. Hence, these are the purposes for developing the flexible Single Point Incremental Forming (SPIF) technology to manufacture the tailored products in small batch production with low tooling cost. It is achieved by localized deformation through single point contact with the polymer sheet. The polymer blank is arrested in a fixture and a small hemispherical tool moves along the pre-defined path in computer numerical controlled (CNC) setup and the blank deforms incrementally to the desired geometry. In this work, the formability, geometrical accuracy and characterization are performed in polymers sheets such as poly vinyl chloride (PVC), polypropylene (PP), polycarbonate (PC), high density poly ethylene (HDPE).

The formability of a sheet metal part is determined with the maximum drawing angle that a material is used. The authors discussed the maximum drawing angle as the response parameter to determine the formability of polymers [1]. Vishal Gulati et al. performed SPIF forming of customized ankle support using CAD model that minimizes the gap between the implanting prosthesis and the ankle [2]. Krzysztof Karbowski et al. developed the skull hole for craniotomy surgery which is produced by polypropylene and polyester knitted yarn manufactured using incremental sheet forming process [3]. Hussain et al formed that truncated cones with continuously varying wall angle is better than truncated cones with constant wall angle to determine the formability of the material [4]. A. Petek et al concluded that forming force is very small in comparison to the deep drawing process and it does not depend on the product size. That is why the production of very large products is absolutely appropriate for forming [5]. P. A. F. Martins et al have done experiments in single point incremental forming of different polymers, and given that the suitability of materials to be processed by SPIF was evaluated [6]. Tania A. Marques et al concluded that SPIF has a high potential for novel applications of rapid prototyping in polymer sheet components with large forming depths [7]. The thickness distribution on a part formed by Incremental Forming, follows the Cosine's law [8]. Surface roughness increases first with increase in incremental depth up to a certain angle and then decreases. Surface roughness value decreases with increase in wall angle [9]. Mohammad Ali et al. studied the micro structural properties in Single Point Incremental Forming of polymers. In PVC, too high tool rotation speed can also cause premature failure of the sheet during forming and the forming forces rise with an increase in the incremental depth [10]. ShakirGatea et al. discuss the process parameters in SPIF and spring back which happens simultaneously with the displacement of the tool, and when the load is removed and dismounted from clamps and the factors affecting spring back values, e.g. tool path, sheet thickness, feed rate, spindle speed, tool size, step size and residual stresses [11].

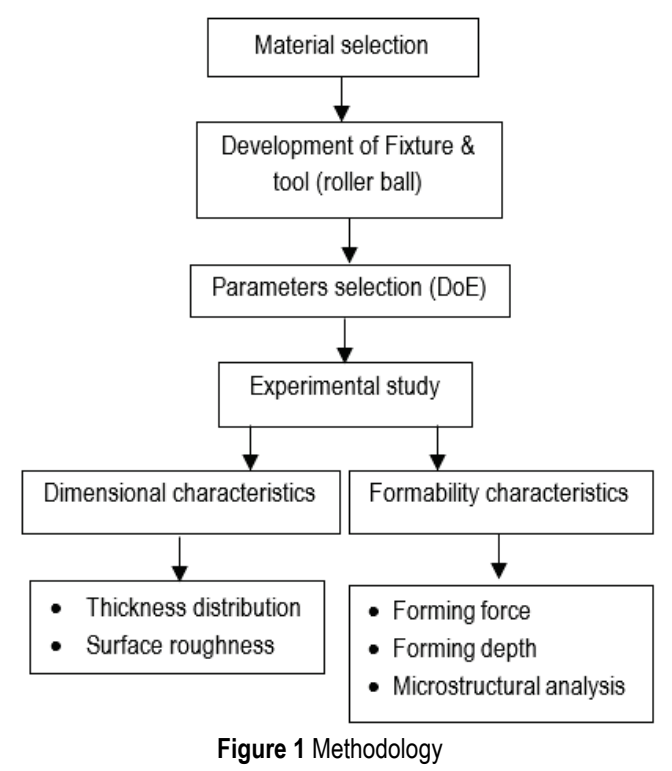

Summarizing the literature, it is identified that very few investigations have been carried out on tooling of SPIF of polymers. This brings out the scope for the investigation 
of roller ball tool on polymer forming using different diameter roller balls on different types of polymer sheets.

\section{EXPERIMENTAL PROCEDURE}

SPIF has proven its potential for producing small batches of sheet metal parts in a wide ranging of materials and geometries. In this section, tooling system, four different materials for SPIF experiments and process parameters selection are discussed with methodology of the research carried out as shown in Fig. 1.

\subsection{CNC Machine}

The experiments are conducted in five-axis $\mathrm{CNC}$ milling machine VMC 850 with a power of $15 \mathrm{~kW}$ at 8000 rpm. Fig. 2 illustrates the SPIF fixture designed for the maximum dimension of $400 \times 400 \mathrm{~mm}$ sheet and it consists of four primary components namely base plate, holding plate, supporting plate and roller ball tool.

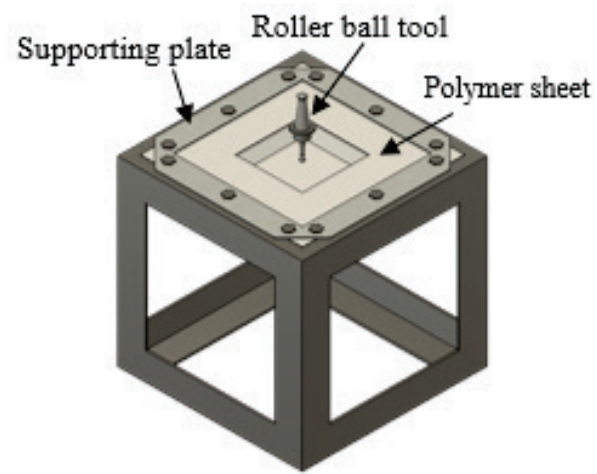

Figure 2 Schematic view of SPIF fixture

The polymer blank is arrested between the supporting plate and the holding plate to avoid sliding of material. The water dissolvable lubricant is used to reduce the excessive friction between the roller ball and polymer sheet interfaces and improves the surface quality. The experimentally arranged SPIF process using roller ball tool is shown in Fig. 3.

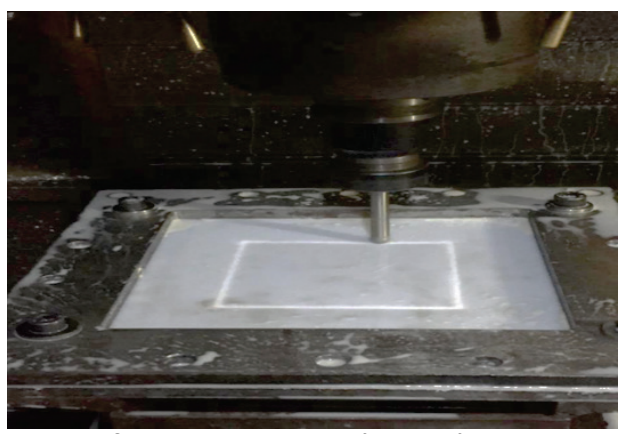

Figure 3 Single point incremental forming of polymer sheet

\subsection{Tooling and Blank Material}

The indigenous roller ball tool is developed with varying ball diameters of $10,12,14$ and $16 \mathrm{~mm}$ as shown in Fig. 4. As the rotating ball has free degree of freedom, the possibility for friction between the tool and material is minimum and also it minimizes the product failure. The tool has freely rotating ball to increase the surface roughness of the material. It is designed and fabricated with HcHcr D2 tool steel. The tool and ball are vacuum hardened to attain the sufficient failure resistance. The blanks of four different polymer sheets namely High Density Polyethylene (HDPE), Polycarbonate (PC), Polyvinylchloride (PVC) and Polypropylene (PP) are used for SPIF. The dimensions of the blank sheets are $400 \times 400$ $\mathrm{mm}$. The material selection is based on the wide industrial applications for polymer sheet products and their properties are indicated in Tab. 1 .

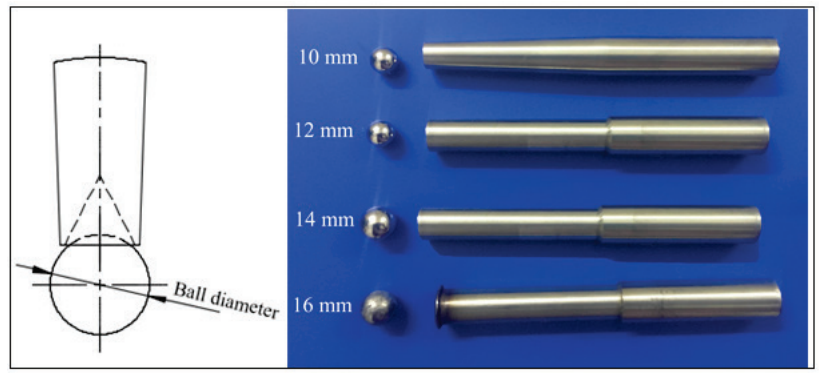

Figure 4 Roller ball tool with various ball diameter

Table 1 Properties of polymer sheets

\begin{tabular}{|l|c|c|c|c|}
\hline \multicolumn{1}{|c|}{ Properties } & PVC & PC & PP & HDPE \\
\hline Yield strength (MPa) & $33-39$ & $42-62$ & $34-36$ & $30-32$ \\
\hline Ultimate strength (MPa) & 52 & $55-75$ & $19-40$ & $34-37.5$ \\
\hline Elastic Modulus (GPa) & $3.3-4$ & $2-2.4$ & 1.75 & 1.35 \\
\hline Elongation at break (\%) & $20-40$ & $80-150$ & $100-600$ & $300-640$ \\
\hline Poisson's Ratio & 0.39 & 0.37 & 0.42 & 0.41 \\
\hline
\end{tabular}

\subsection{Selection of Process Parameters}

The formability on polymer sheets is analysed without any temperature assistance. The significant factors influencing the SPIF process are tool diameter, formed geometry, spindle speed, step size, table feed and material thickness [12]. Taguchi design has been considered for the analysis of optimization of the response parameters involved in the process. In response analysis, three parameters such as surface roughness, thickness distribution and depth of failure are considered. The orthogonal array selected is L16 in which the total number of experiments to be conducted is 16 only which contains the 4 levels of 5 factors in a matrix format. The complete form of the L16 orthogonal array is shown in Tab. 2. The experiments were carried out sequentially.

Table 2 Taguchi DoE of L16 based on orthogonal array

\begin{tabular}{|c|c|c|c|c|c|}
\hline $\begin{array}{c}\text { No. of } \\
\text { Exp. }\end{array}$ & $\begin{array}{c}\text { Tool } \\
\text { diameter } \\
(\mathrm{mm})\end{array}$ & $\begin{array}{c}\text { Step } \\
\text { size } \\
(\mathrm{mm})\end{array}$ & $\begin{array}{c}\text { Sheet thick } \\
(\mathrm{mm})\end{array}$ & $\begin{array}{c}\text { Spindle } \\
\text { speed } \\
(\mathrm{rpm})\end{array}$ & $\begin{array}{c}\text { Table feed } \\
(\mathrm{mm} / \mathrm{min})\end{array}$ \\
\hline 1 & 10 & 0.25 & 1 & 1000 & 600 \\
\hline 2 & 10 & 0.5 & 1.5 & 1500 & 1000 \\
\hline 3 & 10 & 0.75 & 2 & 2000 & 1400 \\
\hline 4 & 10 & 1 & 2.5 & 2500 & 1800 \\
\hline 5 & 12 & 0.25 & 1.5 & 2000 & 1800 \\
\hline 6 & 12 & 0.5 & 1 & 2500 & 1400 \\
\hline 7 & 12 & 0.75 & 2.5 & 1000 & 1000 \\
\hline 8 & 12 & 1 & 2 & 1500 & 600 \\
\hline 9 & 14 & 0.25 & 2 & 2500 & 1000 \\
\hline 10 & 14 & 0.5 & 2.5 & 2000 & 600 \\
\hline 11 & 14 & 0.75 & 1 & 1500 & 1800 \\
\hline 12 & 14 & 1 & 1.5 & 1000 & 1400 \\
\hline 13 & 16 & 0.25 & 2.5 & 1500 & 1400 \\
\hline 14 & 16 & 0.5 & 2 & 1000 & 1800 \\
\hline 15 & 16 & 0.75 & 1.5 & 2500 & 600 \\
\hline 16 & 16 & 1 & 1 & 2000 & 1000 \\
\hline
\end{tabular}




\subsection{Tool Path and Geometry}

The profile is selected as square geometry (Fig. 5). The parallel tool path is selected in this experiment in quasi static condition. Tool path is generated using the MASTERCAM software as shown in Fig. 6. The tool path is kept constant so as to analyze the influence of tool diameter in SPIF process.

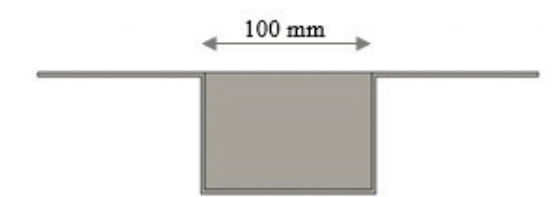

Figure 5 Square geometry: sectional view with dimensions

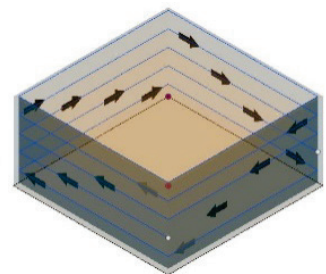

Figure 6 Tool path of square geometry

\subsection{Formability}

As an initial procedure Erichsen cupping test has been performed to evaluate the ductility and formability of the material. The cold plastic deformation is achieved by the depth of indentation. Three trials are performed to check the repeatability. The depth of forming from the cupping test is shown in Fig. 7. The results obtained from cupping tests are considered as significant input in determining the formability of polymer sheets.

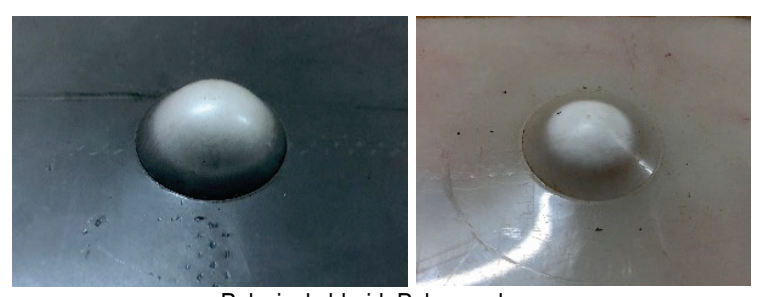

Polyvinyl chloridePolypropylene

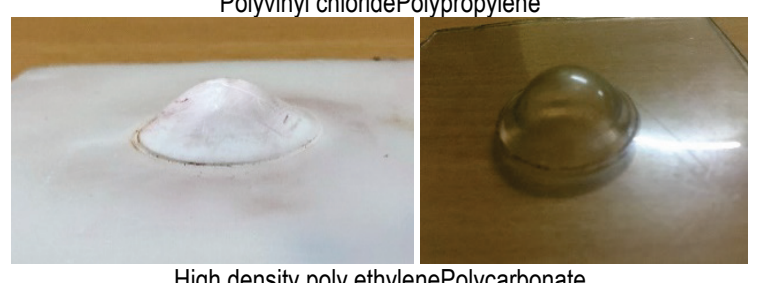

High density poly ethylenePolycarbonate

Figure 7 Erichsen cupping test of polymer sheets

\section{$3 \quad$ RESULT AND DISCUSSIONS}

The results obtained during the SPIF experiments of four different polymer sheets are discussed in the subsequent sections.

\subsection{Failure Analysis}

The process parameters are important to analyse the prediction of failure. The maximum magnitude of deformation obtained before failure is determined as forming limit of the polymer sheet. Fig. 8 shows the macrographs of the incrementally formed parts. It is noticed that the failure occurs in the radial direction, along the wall of the part. The results are in good agreement with failure modes of polymers described by Durante et al. [13]. It is confirmed that the depth of failure is directly proportional to the formability of the polymers. This phenomenon is observed in all four different polymers.

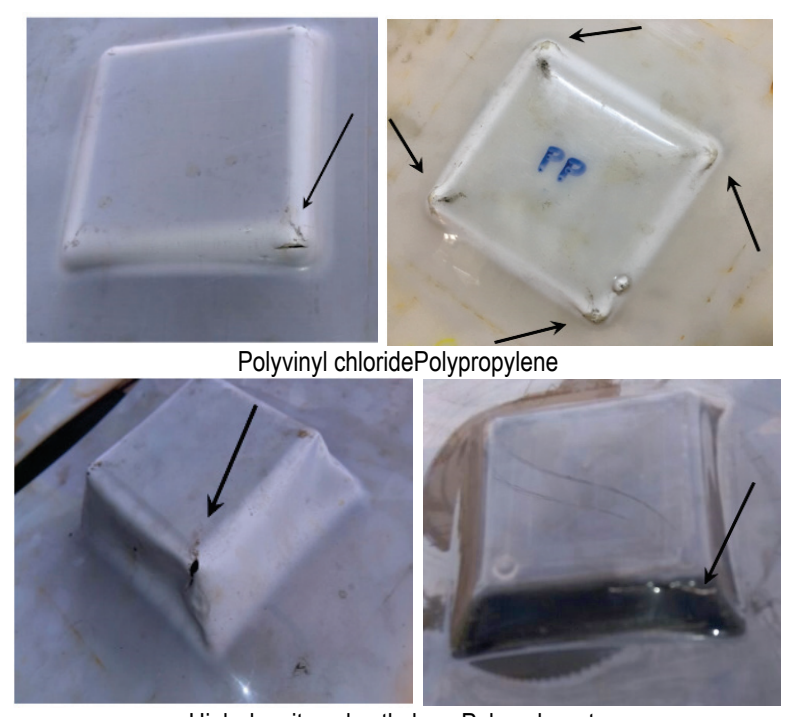

High density poly ethylene Polycarbonate Figure 8 SPIF formed parts

\subsection{Forming Limit Diagram}

Polymers are less resistant to the contraction experienced during the axial stretching by the tool towards the lowermost of the geometry. Fig. 9 implies that the maximum major strain is observed in $\mathrm{PC}$ with an amount of 0.88 and the maximum minor strain observed is -0.09 , that is in second quadrant. HDPE shows the average strain distribution, which indicates the low formability of the material. PVC has very notable agreement with experimental strains and shows good formability. PP shows the poor strain distribution that produces very low formability. The results are closely associated with the results produced by Tania Marques et al. [7].

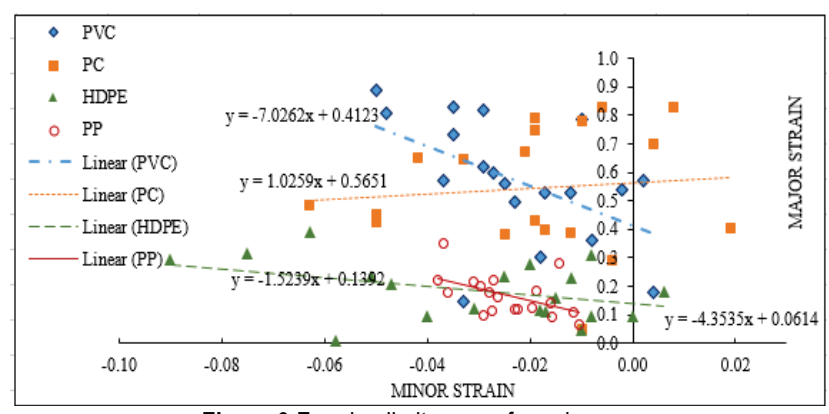

Figure 9 Forming limit curves for polymers

\subsection{Influence of Roller Ball Tool on Sheet Thickness}

The cold plastic deformation of the polymer sheets ends up in the thinning before tearing. So, the higher sheet thickness contributes to the maximum depth of failure. The experimental results plotted in Fig. 10 show increase in sheet thickness increases the maximum depth of failure. It 
is evident with sheet blank of $2.5 \mathrm{~mm}$ thickness provides maximum forming depth than $1 \mathrm{~mm}$ polymer sheet. Similar to the depth of failure, forming force is also responsive to the sheet thickness. It is confirmed from Fig. 11 that the sheet thickness is a governing factor in defining the forming force. The forming force increases with the increase in sheet thickness, irrespective of sheet materials. Among the four ball diameters, $10 \mathrm{~mm}$ produces good surface finish and $16 \mathrm{~mm}$ tool produces high temperature due to friction and it can be noticed in Fig. 4.

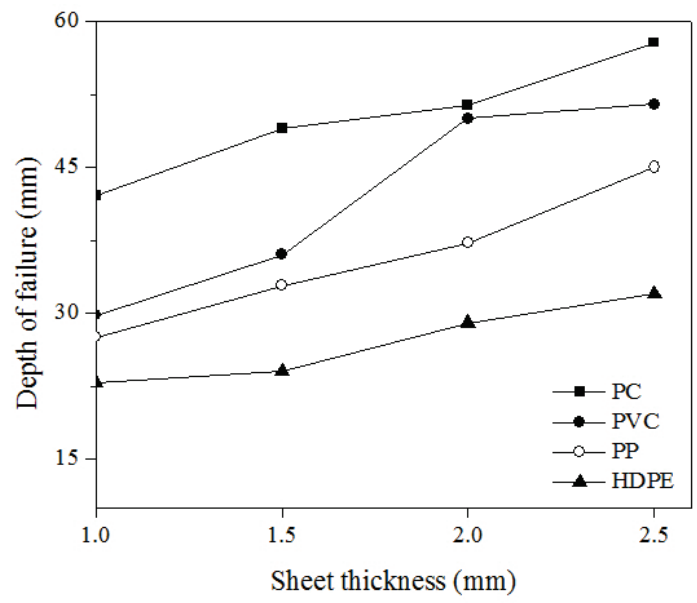

Figure 10 Variation of depth of failure at different sheet thickness

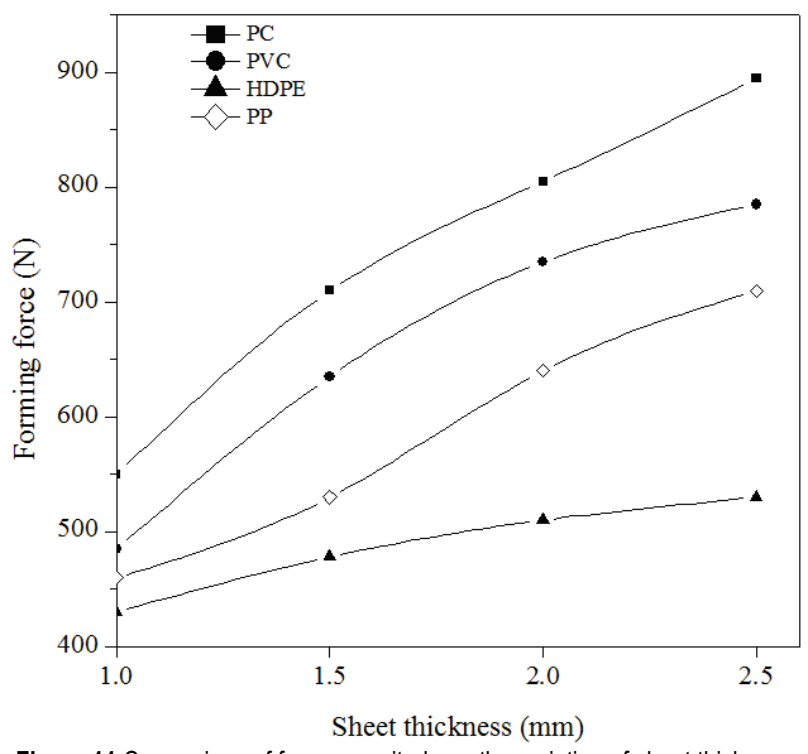

Figure 11 Comparison of force magnitude on the variation of sheet thickness

\subsection{Depth of Failure}

The depth of failure depends on the thinning of the material side wall thickness. It is confirmed from experimental results that $\mathrm{PC}$ is more formable compared to other polymers with respect to the forming depth as shown in Fig. 10. As a means of comparison of forming depth among four different polymer sheets, the maximum and minimum failure depth is $58.42 \mathrm{~mm}$ and $22.7 \mathrm{~mm}$ which are obtained by PC and HDPE respectively. As discussed in the section 3.3 , the sheet thickness is also responsive in determining the depth of failure. Based on the results obtained through experimenting the SPIF on polymers, the following optimized process parameters are concluded in Tab. 3 .
Table 3 Optimized process parameters obtained from experiments

\begin{tabular}{|l|c|}
\hline \multicolumn{1}{|c|}{ Parameter } & Value \\
\hline Tool ball diameter $(\mathrm{mm})$ & 10 \\
\hline Sheet thickness $(\mathrm{mm})$ & 2.5 \\
\hline Spindle speed $(\mathrm{rpm})$ & 1000 \\
\hline Feed $(\mathrm{mm} / \mathrm{rev})$ & 600 \\
\hline Step size $(\mathrm{mm})$ & 0.25 \\
\hline
\end{tabular}

\subsection{Thickness Distribution}

The experimental results show the effectiveness of higher thickness of polymer sheets. The higher the sheet thickness, the higher the forming angle and maximum forming depth is observed. Hence the polymers with higher sheet thickness produce higher SPIF ability comparing with the lower thickness of the same material. This result is in close agreement with the theoretical and experimental results done by Silva et al. [14]. Among the different polymers with $2.5 \mathrm{~mm}$ sheet thickness, polycarbonate shows maximum formability in comparison with other polymers shown in Fig. 12.

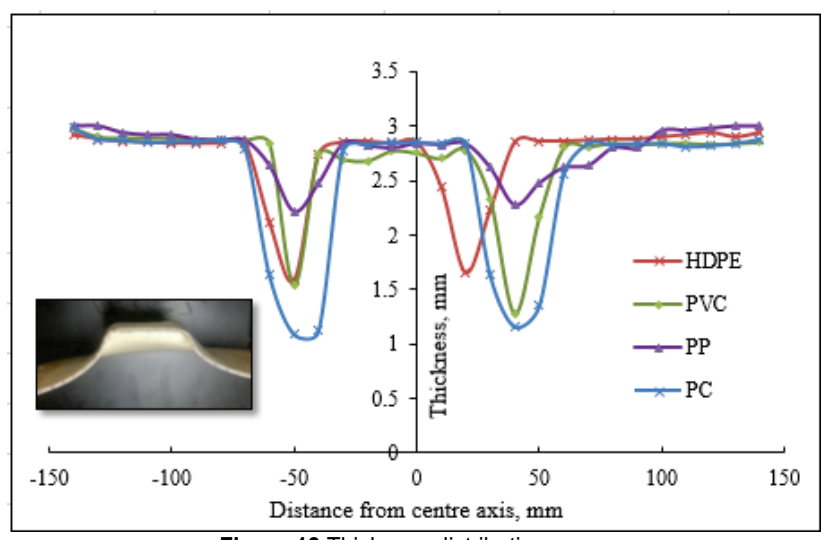

Figure 12 Thickness distribution curve

\subsection{Microstructure Analysis}

In order to study the in-depth understanding of the material behaviour, the microstructural study for four polymer sheets is performed. The microstructure of Polyvinyl chloride shown in Fig. 13(a), shows that particles are dispersed quite uniformly in the polymer matrix throughout a region after forming process. The voids are randomly distributed in the base polymer structure. Since it is a cold forming process, the polymer chains are elongated in the deforming direction. The tearing of polymer at some point is due to the inability to withstand the shearing load. A failure model of voids and cracks indicates the toughness during the forming process by the induced orientation of polymer chains and the formation of voids. Fig. 13(b) shows the before and SPIF formed microstructure of PC. The black dots in the base structures are the voids, formed during chain formation of polymers. The straining causes the voids to squeeze out. The colour of polymer sheet has become dark in PC after forming due to the burning effect of the relative motion between the tool and sheet.

Fig. 14(a), shows the before formed and SPIF formed microstructure of HDPE. The failure of the SPIF polymer sheet occurs with the breakage of bond due to work hardening effect at a particular point and the failure occurs due to tearing. A surface damage is found in the tool 
travelling path which occurs due to poor lubrication in SPIF formed HDPE material. Microstructure of PP (Fig. 14(b)), shows that particles are dispersed quite uniformly in the polymer matrix after forming process, but frequently they tend to form small agglomerates. In general, the amount and size of the agglomerates increases with increasing of the load, polymer chain orientation, recrystallization of the amorphous regions, and void formation in the presence of fumed nanoparticles which are believed to have beneficial effects on mechanical properties of the formed sheet.
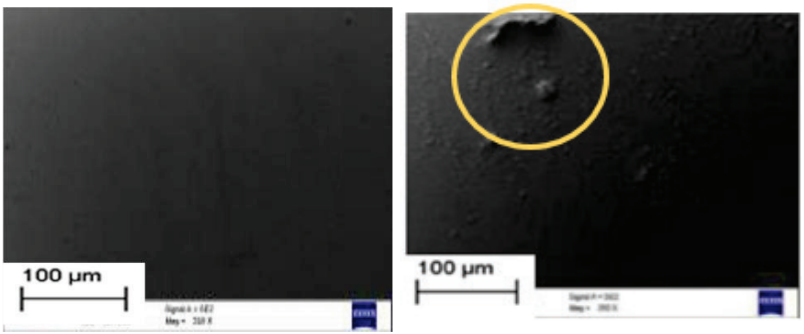

(a) Base structure - PVCSPIF formed microstructure - PVC
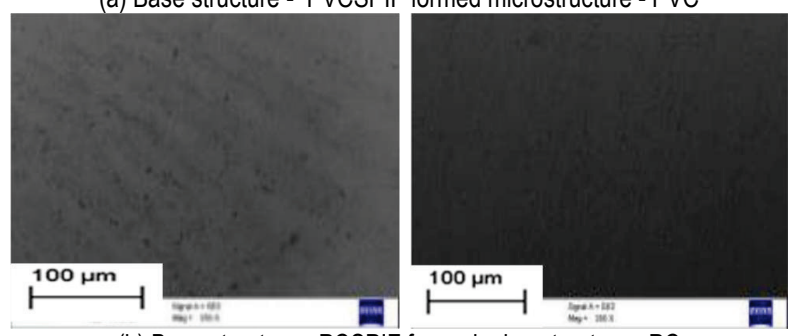

(b) Base structure - PCSPIF formed microstructure - PC Figure 13 Microstructure of polymer sheets (a) PVC (b) PC
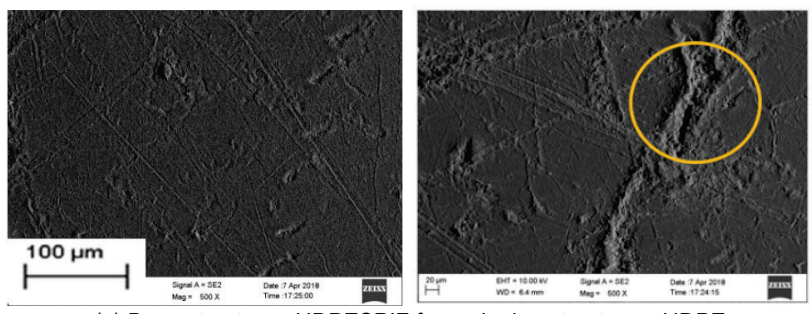

(a) Base structure - HDPESPIF formed microstructure - HDPE
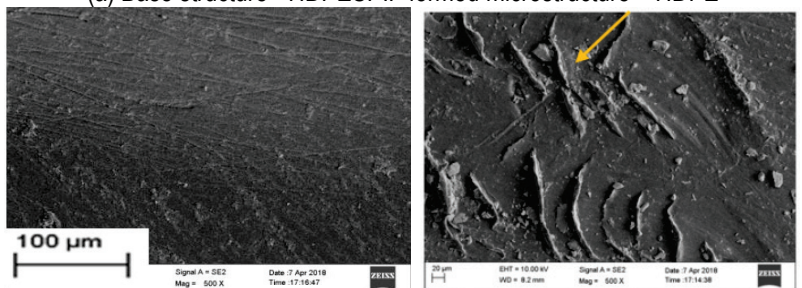

(b) Base structure - PPSPIF formed microstructure - PP

Figure14 Microstructure of polymer sheets (a) HDPE (b) PP

\subsection{Surface Roughness}

The combined variation of roughness of each material is plotted in Fig. 15. The forming process reduces the surface quality in polymer even though all the initial roughness values are almost same. At the bottom face, the different polymer materials show different values depending upon its deformation. The surface roughness is inversely proportional to thinning percentage. If thinning percentage increases with increase of plastic deformation, the surface roughness decreases.

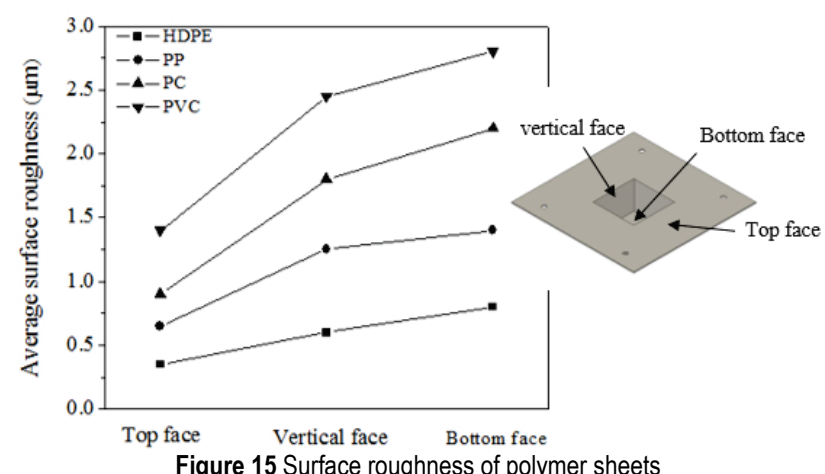

\section{CONCLUSION}

The cold plastic deformation of polymers depends on the applied stress. By varying the levels, it is reflected in different yielding of polymer sheets. The SPIF of polymers are investigated by indigenous SPIF roller ball tool. The main contributions from this experimental work are analysis of formability of polymers with roller ball diameter, formability of polymers by varying process parameters. The material type and thickness also depend on selecting roller ball diameter to attain maximum formability. The surface roughness is inverse to thinning percentage. Based on the experimental results obtained the following conclusions are made:

- A small tool diameter produces better surface quality than a bigger ball diameter.

- The bigger tool diameter produces high temperature due to friction

- The material deformation of PP in SPIF is higher than the HDPE.

- $\quad P P$ is preferred for large size components with tolerance.

- $\quad \mathrm{PC}$ is considered for precision components as it provides minimum surface roughness and is suggested for high surface quality components. It presents the key feature of keeping transparency after being plastically deformed.

- PVC shows the springback resistance and can be used for high accuracy component. The Cracks are observed to be formed in the circumferential route on the transition area among the bottom and side wall portion.

The in-depth investigation of polymers using roller ball tool is conducted which yields comparable results. The investigation can further be performed using different lubricants and different polymer sheets which yields even better results for the development of manufacturing prototype parts.

\section{REFERENCES}

[1] Martins, P. A. F., Bay, N., Skjoedt, M. \& Silva, M. B. (2008). Theory of single point incremental forming. CIRP Annals Manufacturing Technology, 57, 247-252. https://doi.org/10.1016/j.cirp.2008.03.047

[2] Silva, M. B., Nielsen, P. S., Bay, N. \& Martins, P. A. F. (2011). Failure mechanisms in single-point incremental forming of metals. International Journal of Advanced Manufacturing Technology, 56(9), 893-903. https://doi.org/10.1007/s00170-011-3254-1 
[3] Karbowski, K. (2015). Application of Incremental Sheet Forming. Management and Production Engineering Review, 6(4), 55-59. https://doi.org/10.1515/mper-2015-0036

[4] Hussain, G., Gao, L., Hayat, N. \& Ziran, Xu. (2009). A new formability indicator in single point incremental forming. Journal of Materials Processing Technology, 209, 42374242. https://doi.org/10.1016/j.jmatprotec.2008.11.024

[5] Petek, A., Kuzman, K., \& Kopac, J. (2009). Deformations and forces analysis of single point incremental sheet metal forming. Archives of Materials Science and Engineering, 35(2) 107-116.

[6] Martins, P. A. F., Kwiatkowski, L., Franzen, V., Tekkaya, A. E. \& Kleiner, M. (2009), Single point incremental forming of polymers. CIRP Annals - Manufacturing Technology, 59(1), 229-232. https://doi.org/10.1016/j.cirp.2009.03.095

[7] Marques, A. T., Silva, M. B. \& Martins, P. A. F. (2012), On the potential of single point incremental forming of sheet polymer parts. International journal of advanced manufacturing technology, 60(1), 75-86. https://doi.org/10.1007/s00170-011-3585-y

[8] Hussain, G. \& Gao, L. (2007), A novel method to test the thinning limits of sheet metals in negative incremental forming. International Journal of Machine Tools \& Manufacture, 47, 419-435. https://doi.org/10.1016/j.jimachtools.2006.06.015

[9] Bhattacharya, A., Maneesh, K., Venkata Reddy., N. \& Cao, J. (2011), Formability and Surface Finish Studies in Single Point Incremental Forming. Journal of Manufacturing Science and Engineering, 133(6), 10-20. https://doi.org/10.1115/MSEC2011-50284

[10] Davarpanah, M. A., Mirkouei, A., Yu, X., Malhotra, R., \& Pilla, S. (2015). Effects of incremental depth and tool rotation on failure modes and microstructural properties in Single Point Incremental Forming of polymers. Journal of material processing technology, 222, 287-300. https://doi.org/10.1016/j.jmatprotec.2015.03.014

[11] Gatea, S., Ou, H., \& McCartney, G. (2016). Review on the influence of process parameters in incremental sheet forming. International Journal of Advanced Manufacturing Technology, 87(1) 479-499. https://doi.org/10.1007/s00170-016-8426-6

[12] Ham, M. \& Jeswiet, J. (2007). Forming Limit Curves in Single Point Incremental Forming. Annals of the CIRP, 56, 277-280. https://doi.org/10.1016/j.cirp.2007.05.064

[13] Durante, M., Formisano, A., \& Lambiase, F. (2018). Incremental forming of polycarbonate sheets. Journal of Materials processing Tech., 253, 57-63. https://doi.org/10.1016/j.jmatprotec.2017.11.005

[14] Silva, M. B., Alves, L. M., \& Martins, P. A. F. (2010). Single point incremental forming of PVC: Experimental findings and theoretical interpretation. European Journal of Mechanics, 29, 557-566. https://doi.org/10.1016/i.euromechsol.2010.03.008

\section{Contact information:}

Karthik THANGAVEL, M.E., Assistant Professo

(Corresponding author)

Department of Mechanical Engineering

PSG College of Technology

Peelamedu, Coimbatore - 641 004, India

tkarthik.psg@gmail.com

Rajenthirakumar DURAISWAMY, M.E., Ph.D., Professor Department of Mechanical Engineering

PSG College of Technology

Peelamedu, Coimbatore - 641 004, India

rajentkumar@gmail.com

Srinivasan NAGARAJAN, M.E., Research scholar

Department of Mechanical Engineering

PSG College of Technology

Peelamedu, Coimbatore - 641 004, India

srini.prs@gmail.com

Sridhar RAMASAMY, M.E., Ph.D., Assistant Professor Department of Mechanical Engineering

PSG College of Technology

Peelamedu, Coimbatore - 641004 , India

sridhar.sulur@gmail.com 